500 Jahre Reformation 



\section{Jahre Reformation}

Rückblicke und Ausblicke aus interdisziplinärer Perspektive

Herausgegeben von

Peter Opitz

\section{DE GRUYTER \\ OLDENBOURG}


ISBN 978-3-11-054009-3

e-ISBN (PDF) 978-3-11-054241-7

e-ISBN (EPUB) 978-3-11-054031-4

\section{Library of Congress Control Number: 2018945660}

\section{Bibliografische Information der Deutschen Nationalbibliothek}

Die Deutsche Nationalbibliothek verzeichnet diese Publikation in der Deutschen Nationalbibliografie; detaillierte bibliografische Daten sind im Internet über http://dnb.dnb.de abrufbar.

(C) 2018 Walter de Gruyter GmbH, Berlin/Boston

Abbildung auf dem Cover: Der uralten wytbekannten Statt Zürych Gestalt und Gelaegenheit, wie sy zu diser Zyt in waesen. Zürich, [1878] (Murer, Jos), Zentralbibliothek Zürich, Signatur: 5 Lb 02: 6 + 3 Lb 02: 2 [Persistenter Link: http://dx.doi.org/10.3931/e-rara-28029] Druck und Bindung: $\mathrm{CPI}$ books $\mathrm{GmbH}$, Leck

www.degruyter.com 